\title{
Early abolition of cough reflex predicts mortality in deeply sedated brain-injured patients
}

\author{
Stanislas Kandelman ${ }^{1,2}$, Jérémy Allary ${ }^{1}$, Raphael Porcher ${ }^{3}$, Cássia Righy ${ }^{4,5}$, Clarissa Francisca Valdez ${ }^{4,6}$, Frank \\ Rasulo $^{7,8}$, Nicholas Heming ${ }^{9}$, Guy Moneger ${ }^{9}$, Eric Azabou ${ }^{10}$, Guillaume Savary ${ }^{1}$, Djillali Annane ${ }^{9}$, Fabrice \\ Chretien $^{11}$, Nicola Latronico ${ }^{7,8}$, Fernando Augusto Bozza ${ }^{5,12}$, Benjamin Rohaut ${ }^{\text {Corresp., 13, } 14}$, Tarek Sharshar ${ }^{\text {Corresp. } 11,12,15}$ \\ ${ }^{1}$ Department of Anesthesiology and Intensive Care Unit, Beaujon Hospital, University Denis Diderot, Clichy, France \\ 2 Department of Anesthesia, Royal Victoria Hospital, McGill University Health Center, Montréal, Québec, Canada \\ 3 Center for Clinical Epidemiology, Assistance Publique Hôpitaux de Paris, Hotel Dieu Hospital, University Paris Descartes, Paris, France \\ 4 Intensive Care Unit, Instituto Estadual do Cérebro Paulo Niemeyer, Rio de Janeiro, Brazil \\ 5 Instituto Nacional de Infectologia Evandro Chagas, Fundação Oswaldo Cruz (Fiocruz), Rio de Janeiro, Brazil \\ 6 Intensive Care Unit, Hospital das Américas, Rio de Janeiro, Brazil \\ 7 Department of Anesthesia, Critical Care and Emergency, Spedali Civili University Hospital, Brescia, Italy \\ 8 Department of Medical and Surgical Specialties, Radiological Sciences and Public Health, University of Brescia, Brescia, Italy \\ 9 General Intensive Care Unit, Assistance Publique Hôpitaux de Paris, Raymond-Poincaré Hospital, University of Versailles Saint-Quentin en Yvelines, \\ Garches, France \\ 10 Department of Physiology, INSERM U 1179, Assistance Publique Hôpitaux de Paris, Raymond-Poincaré Hospital, University of Versailles Saint-Quentin \\ en Yvelines, Garches, France \\ 11 Laboratory of Human Histopathology and Animal Models, Institut Pasteur, Paris, France \\ 12 D'Or Institute for Research and Education, Rio de Janeiro, Brazil \\ 13 Department of Neurology, Intensive Care Unit, Groupe Hospitalier Pitié-Salpêtrière, AP-HP, Paris, Sorbonne Universités, Faculté de Médecine Pitié- \\ Salpêtrière, Paris, France, Paris, France \\ 14 Department of Neurology, Critical Care Neurology, Columbia University, New York, USA \\ 15 Neuro-Anesthesiology and Intensive Care Unit, Sainte-Anne Teaching Hospital, University of Paris-Descartes, Paris, France \\ Corresponding Authors: Benjamin Rohaut, Tarek Sharshar \\ Email address: br2529@columbia.edu, t.sharshar@ch-sainte-anne.fr
}

ABSTRACT Background: Deep sedation may hamper the detection of neurological deterioration in brain-injured patients. Impaired brainstem reflexes within the first 24 hours of deep sedation are associated with increased mortality in non-brain-injured patients. Our objective was to confirm this association in brain-injured patients. Methods: This was an observational prospective multicenter cohort study involving four neurointensive care units. We included acute brain-injured patients requiring deep sedation, defined by a Richmond Assessment Sedation Scale (RASS) < - 3. Neurological assessment was performed at day 1 and included pupillary diameter, pupillary light, corneal and cough reflexes, and grimace and motor response to noxious stimuli. Pre-sedation Glasgow Coma Scale (GCS) and Simplified Acute Physiology Score (SAPS-II) were collected, as well as the cause of death in the Intensive Care Unit (ICU). Results: 137 brain-injured patients were recruited, including $70(51 \%)$ traumatic brain-injured patients, 40 (29\%) vascular (subarachnoid haemorrhage or intracerebral haemorrhage). Thirty patients (22\%) died in 
the ICU. At day 1 , the corneal (OR 2.69, $p=0.034$ ) and cough reflexes (OR 5.12, $p=0.0003$ ) were more frequently abolished in patients that died in the ICU. In a multivariate analysis, abolished cough reflex was associated with ICU mortality after adjustment to pre-sedation GCS, SAPS-II, RASS (OR: 5.19, 95\% Cl: [1.92-14.1], $\mathrm{p}=0.001$ ) or dose of sedatives (OR: 8.89, 95\% Cl: [2.64-30.0], $p=0.0004$ ). Conclusion: Early (day 1 ) cough reflex abolition is an independent predictor of mortality in deeply sedated brain-injured patients. Abolished cough reflex likely reflects a brainstem dysfunction that might result from the combination of primary and secondary neuro-inflammatory cerebral insults revealed and/or worsened by sedation. 


\section{Early abolition of cough reflex predicts mortality in deeply sedated}

2

\section{brain-injured patients}
Stanislas Kandelman, MD ${ }^{1,2}$; Jeremy Allary, $\mathrm{MD}^{1}$; Raphaël Porcher,PhD; Cássia Righy, MD, PhD',5; Clarissa Francisca Valdez, MD ${ }^{5,6}$, Frank Rasulo, MD ${ }^{7,8}$; Nicholas Heming, MD, $\mathrm{PhD}^{9}$; Guy Moneger, $\mathrm{MD}^{9}$; Eric Azabou, MD, $\mathrm{PhD}^{10}$; Guillaume Savary, $\mathrm{MD}^{1}$; Djillali Annane, $\mathrm{MD}, \mathrm{PhD}^{9}$; Fabrice Chrétien, $\mathrm{MD}, \mathrm{PhD}^{11}$; Nicola

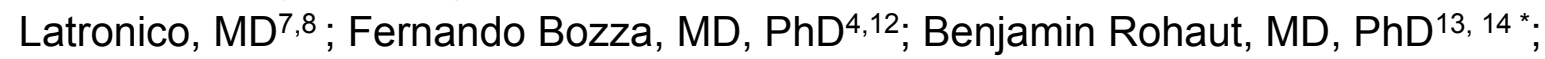 Tarek Sharshar, MD, PhD 11,12,15*

1 Department of Anesthesiology and Intensive Care Unit, Beaujon Hospital, University Denis Diderot - Clichy, France

${ }^{2}$ Department of Anesthesiology, Royal Victoria Hospital, McGill University Health Center, Montreal, Canada

${ }^{3}$ Center for Clinical Epidemiology, Assistance Publique Hôpitaux de Paris, Hôtel Dieu Hospital, University Paris Descartes - France, France

${ }^{4}$ Instituto Nacional de Infectologia Evandro Chagas, Fundação Oswaldo Cruz (Fiocruz), Rio de Janeiro, Brazil

${ }^{5}$ Intensive Care Unit, Instituto Estadual do Cérebro Paulo Niemeyer, Rio de Janeiro, Brazil

${ }^{6}$ Intensive Care Unit, Hospital das Américas, Rio de Janeiro, Brazil

${ }^{7}$ Department of Anesthesia, Critical Care and Emergency, Spedali Civili University Hospital, Brescia, Italy

${ }^{8}$ Department of Medical and Surgical Specialties, Radiological Sciences and Public Health, University of Brescia, Italy

${ }^{9}$ General Intensive Care Unit, Assistance Publique Hôpitaux de Paris, Raymond-Poincaré Hospital, University of Versailles Saint-Quentin en Yvelines - Garches, France

${ }^{10}$ Department of Physiology, INSERM U1179, Assistance Publique Hôpitaux de Paris, RaymondPoincaré Hospital, University of Versailles Saint-Quentin en Yvelines - Garches, France

11 Laboratory of Human Histopathology and Animal Models, Institut Pasteur, Paris, France

12 D'Or Institute for Research and Education, Rio de Janeiro, Brazil

${ }^{13}$ Department of Neurology, Intensive Care Unit, Groupe Hospitalier Pitié-Salpêtrière, AP-HP, Paris, Sorbonne Universités, Faculté de Médecine Pitié-Salpêtrière, Paris, France.

${ }^{14}$ Department of Neurology, Critical Care Neurology, Columbia University, New York, USA

15 Neuro-Anesthesiology and Intensive Care Unit - Sainte-Anne Teaching Hospital, University of

Paris-Descartes - Paris, France

${ }^{*}$ Equal contribution

Peer] reviewing PDF | (2019:05:37617:1:2:NEW 6 Oct 2020) 
36 Corresponding author:

37 Pr Tarek Sharshar, MD, PhD

38 Paris-Descartes University, Department of neuro-anesthesiology and intensive care

39 medicine, Sainte-Anne Teaching Hospital; 1 rue cabanis 75014 Paris France

40 Tel +33 1456573 00; Email: t.sharshar@ch-sainte-anne.fr

41 Laboratory of human histopathology and animal models

42 Institut Pasteur, 28 rue du Dr Roux, 75015 Paris France; Email: tsharshar@pasteur.fr

43

44 Dr Benjamin Rohaut, MD, PhD

45 Email : Br2529@columbia.edu

Word and element count: Abstract: 257 words; words count: 3372; Number of Figures:

1; Number of Tables: 4

Short title: Brainstem dysfunction in NeurolCU

Financial Disclosure Statement: Authors have no conflict of interest to disclose.

Support was provided solely from institutional and/or departmental sources.

Keywords: Brain injury, Deep sedation, Brainstem dysfunction, Neuroprognosis. 


\section{ABSTRACT}

58

Background: Deep sedation may hamper the detection of neurological deterioration in brain-injured patients. Impaired brainstem reflexes within the first 24 hours of deep sedation are associated with increased mortality in non-brain-injured patients. Our objective was to confirm this association in brain-injured patients.

Methods: This was an observational prospective multicenter cohort study involving four neuro-intensive care units. We included acute brain-injured patients requiring deep sedation, defined by a Richmond Assessment Sedation Scale (RASS) $<-3$.

Neurological assessment was performed at day 1 and included pupillary diameter, pupillary light, corneal and cough reflexes, and grimace and motor response to noxious stimuli. Pre-sedation Glasgow Coma Scale (GCS) and Simplified Acute Physiology Score (SAPS-II) were collected, as well as the cause of death in the Intensive Care Unit (ICU).

Results: 137 brain-injured patients were recruited, including 70 (51\%) traumatic braininjured patients, $40(29 \%)$ vascular (subarachnoid haemorrhage or intracerebral haemorrhage). Thirty patients (22\%) died in the ICU. At day 1, the corneal (OR 2.69, $p=0.034)$ and cough reflexes (OR $5.12, p=0.0003$ ) were more frequently abolished in patients that died in the ICU. In a multivariate analysis, abolished cough reflex was associated with ICU mortality after adjustment to pre-sedation GCS, SAPS-II, RASS (OR: $5.19,95 \% \mathrm{Cl}:[1.92-14.1], \mathrm{p}=0.001$ ) or dose of sedatives (OR: $8.89,95 \% \mathrm{Cl}$ : [2.6430.0], $p=0.0004)$. 
78 Conclusion: Early (day 1) cough reflex abolition is an independent predictor of mortality

79 in deeply sedated brain-injured patients. Abolished cough reflex likely reflects a

80 brainstem dysfunction that might result from the combination of primary and secondary

81 neuro-inflammatory cerebral insults revealed and/or worsened by sedation. 
82

83

84

85

86

87

88

89

90

91

92

93

94

95

\section{INTRODUCTION}

Patients with severe brain injury frequently receive early deep sedation (Oddo et al., 2016). Deep sedation may improve cerebral hemodynamics by reducing the rate of cerebral oxygen consumption and by decreasing intracranial pressure. However, deep sedation may also delay awakening, induce delirium (Oddo et al., 2016) and, increase mortality (Shehabi et al., 2018). In addition, sedation hampers clinical assessment of neurological status in brain-injured patients, potentially masking acute neurological worsening. Deep sedation also compromises the assessment of the patient's prognosis, which then relies on the pre-sedation examination (such as Glasgow Coma Scale). It is therefore challenging for ICU-physicians to routinely assess the neurological status of severely brain-injured patients requiring deep sedation. Nonetheless, ICU physicians have at their disposal various tools, including neurological examination and electrophysiological testing. The main difficulty, then, is to distinguish the effects of sedation from the consequences of underlying brain injury on clinical signs and the activity of the electroencephalogram (EEG). This is a highly complex situation compounded by the existence of both primary and secondary brain insults. Clinical relevance of neurological examination - especially brainstem reflex assessment - has previously been demonstrated in non-brain-injured, critically-ill patients (Foo, Loan \& Brennan, 2019), including deeply sedated patients (Sharshar et al., 2011a; Rohaut et al., 2017; Azabou et al., 2017, 2018). Assessment of brainstem reflexes is feasible and reproducible, and constitutes an early independent predictor of ICU-mortality, after adjustment to critical illness severity, sedation level, and sedative doses in non-braininjured, critically ill patients (Sharshar et al., 2011a; Rohaut et al., 2017; Azabou et al., 
105

106

107

108

109

110

111

112

113

114

115

116

117

118

119

120

121

122

123

124

125

126

127

2017, 2018). Our pathophysiological hypothesis is that critical illness may be associated with brainstem dysfunction, which might itself be caused by the combined effects of critical illness and sedation, and may contribute to mortality, notably via a central autonomic dysfunction (Sharshar et al., 2011a; Rohaut et al., 2017; Benghanem et al., 2020).

A previousstudy has shown the prognostic value of early (day 1) assessment of brainstem reflexes in deeply sedated, non-brain-injured patients (Sharshar et al., 2011a). The main objective of the present study was to extend these previous findings to brain-injured patients.

\section{MATERIAL AND METHODS}

\section{Study design and setting}

This was a prospective, multicenter, international observational cohort study, approved by the ethics committee of Paris (lle de France IV), France (Approval number 2014AO1102-45) and Brescia (NP 1840, 04-11-2014), Italy. Written informed consent was obtained from the patients' legal representative in France. In Italy, the Ethics Committee waived the requirement for consent because relatives are not regarded as legal representatives of the patient in the absence of a formal designation. The current study was a pilot study preceding the design of a larger prospective multicentre study assessing the prognostic value of brainstem dysfunction in sedated critically ill patients (ClinicalTrials.gov number: NCT02395861). Patients were recruited in four intensive care units, including one neuro ICU and three medical and surgical ICUs. Patients were recruited between December 2011 and February 2015. The Strengthening the 
128 Reporting Studies in Epidemiology (STROBE) guidelines were followed thoroughly (von

129 Elm et al., 2007).

\section{Participants}

131 Adult patients were eligible if they were deeply sedated following a major brain injury:

132 severe traumatic brain injury, subarachnoid or intraparenchymal cerebral haemorrhage,

133 ischemic stroke, or following a complicated neurosurgical or endovascular procedure.

134 Deep sedation was defined by a Richmond Assessment Sedation Scale (RASS) score

$135<-3$ (Ely et al., 2003). Patients were included if sedation lasted between 12 and 24

136 hours, and could be neurologically assessed by one of the PI (SK, JA, CR, CV, FR, NH,

137 GM, GS, NL and FB) at working hours.

138 Patients were excluded if they were affected by a peripheral neurologic disorder

139 involving the cranial nerves (e.g., Guillain Barré syndrome), or had been referred

140 following cardiac arrest. Based on our previous findings in non-brain-injured patients,

141 we planned to include 150 patients in the present study (Sharshar et al., 2011a; Rohaut 142 et al., 2017).

\section{Sedation}

144 Decisions to initiate or to withdraw sedation as well as the level of sedation were made by the physician in charge of the patient. We recorded the time and reason for initiating deep sedation as well as the Glasgow Coma Scale (GCS) prior to sedation. Since sedation was administered as part of the treatment of the cerebral insult, no systematic interruptions of sedation or decreasing trials were performed during the first 24 hours.

149 Nevertheless, depth of sedation was monitored using the RASS every four hours. After 150 the first 24 hours, the possibility of discontinuing sedation was assessed on a daily 
151 basis. Titration of sedation was performed at least twice daily, targeting physician in

152 charge-defined RASS levels. The date of awakening, defined by spontaneous eye

153 opening and visual contact $>10$ sec (i.e., RASS $\geq-1$ ), was recorded.

154 Sedation was obtained through a continuous infusion of midazolam and/or propofol, in

155 combination with sufentanil or fentanyl. Total cumulative doses of administered drugs at

156 the time of neurologic examination were collected.

\section{Neurologic examination}

158 The detailed procedure pertaining to neurological examination has been previously

159 described (Sharshar et al., 2011a). Briefly, we assessed: 1) depth of sedation (RASS);

160 2) reactivity, using the motor and eye response components of the GCS; 3) brainstem

161 reflexes, including pupil size (miosis, normal, or mydriasis), pupillary light reflex, corneal

162 reflex, facial muscle movement in response to noxious stimulation of the temporo-

163 mandibular joint, and the cough reflex in response to tracheal suctioning.

164 Neurologic examination was performed after $24 \pm 12$ hours of continuous sedation (day

165 1). Retaining the same definition used in our previous studies, corneal and pupillary

166 reflexes were considered abolished only when both right and left side reflex were

167 abolished. The oculocephalic response to lateral passive head rotation was not

168 performed in traumatic brain injured patients. The Full Outline of Unresponsiveness

169 (FOUR) score was recorded (Wijdicks et al., 2005). At the time of neurological

170 examination, intracranial pressure (ICP) was recorded if available. Intracranial

171 hypertension was defined as ICP $>25 \mathrm{mmHg}$ lasting for more than 5 minutes or by the

172 need of an additional treatment to control the intracranial pressure (additional sedative 
173 agent, ventricular drainage, craniotomy with hematoma evacuation or decompressive

174 craniectomy).

\section{Baseline clinical and biological and imaging data}

176 Demographic characteristics, body weight, date, time and cause of ICU admission, co-

177 morbidities using McCabe score (McCabe \& Jackson, 1962), date of invasive

178 mechanical ventilation (MV) initiation and its duration, ICU length of stay, occurrence of

179 microbiologically documented ventilator-associated pneumonia as well as the date and

180 cause of death were recorded. The Simplified Acute Physiological Score II (SAPS-II)

181 (Le Gall et al., 2005), the Sequential Organ Failure Assessment (SOFA) (Vincent et al.,

182 1996) as well as key interventions and standard biological tests needed to calculate

183 these scores were recorded. Clinical, biological and neuroradiological data were

184 collected as part of the routine care.

185 The presence or absence of infratentorial lesions, including brainstem lesions, was

186 assessed on the first cerebral computed tomography scanner (CT-scan) performed

187 within 24 hours following ICU admission, by the senior neuroradiologist and ICU

188 physician in charge.

\section{Outcomes}

191 Primary recorded outcome was ICU mortality. Secondary outcomes were the

192 occurrence of delayed awakening and of delirium following sedation discontinuation.

193 Delayed awakening was defined by RASS<-1 despite discontinuation of sedation for

194 more than 72 hours. Delirium was assessed daily using the confusion assessment

195 method for the ICU (CAM-ICU) (Ely et al., 2001). Other secondary outcomes were the

196 duration of mechanical ventilation, the length of stay in the ICU and the occurrence of 
197 microbiologically documented ventilator-associated pneumonia. Patients had follow-up 198 until ICU discharge.

199 Withdrawal of life-sustaining therapies (WLST) was determined according to applicable 200 French and Italian Law. In current practice, no such decision involves the result of early 201 neurological examination in a deeply-sedated patient.

202

203

204

205

206

207

208

209

210

211

212

213

214

215

216

217 218

\section{Bias and confounding factors}

We sought to mitigate potential confounding factors that might influence neurological examination as well as relevant outcomes, namely mortality and the occurrence of delirium. Neurological examination was performed by senior ICU physicians who were either neurologists or neuro-intensivists, or were specifically trained by a senior neurologist. The investigator was different from the clinician in charge of the patient. Inter-observer agreement for such an examination has been shown to be satisfactory (kappa scores ranged from 0.62 to 1) (Sharshar et al., 2011b). Brainstem reflexes are routinely assessed in neuro-ICU patients. Management of deep sedation was assessed by collecting cumulative doses and duration of sedation as well as daily RASS. The cause of death and its main risk factors were also assessed, including the GCS prior to sedation, SAPS-II and the SOFA score as well as the cause of brain injury.

\section{Statistical Analysis}

Data are reported as numbers (percentage), mean (standard deviation), or median (inter-quartile range). Groups were compared using the Wilcoxon rank sum test or the 
219 chi-square test. Logistic regression was used to explore the associations between the

220 pre-sedation GCS, SAPS-II, RASS scores, sedation doses, cough reflex, corneal reflex,

221 and ICU mortality. These variables were determined a priori according to our previous

222 findings (Rohaut et al., 2017). Since the number of events was limited, we used Firth

223 penalized logistic regression for multivariable models, in order to limit small-sample

224 bias. Discrimination of multivariable models was assessed using the concordance (c)

225 index, which is equivalent to the area under the receiver operating characteristics curve.

226 It varies theoretically between 0.5 and 1.0 , a value of 1.0 indicating a perfect

227 discrimination. Missing data were handled by multiple imputation by chained equations,

228 all variables considered for analysis being used in the imputation model. Since about

229 half patients had at least one variable missing (35 patients had missing data for one

230 variable, one had missing data for seven), 50 imputed datasets were generated (White,

231 Royston \& Wood, 2011). Each imputed dataset was analysed separately, and estimates

232 were then pooled to provide point estimates and confidence intervals (Cl) (Marshall et

233 al., 2009). P-values < 0.05 were considered as statistically significant. All analyses were

234 carried out using the R statistical software version 3.4.1 (The R Foundation for

235 Statistical Computing, Vienna, Austria).

236 RESULTS

\section{Patient characteristics}

238

239

240

241

Among 151 consecutive brain injured patients receiving deep sedation within 12 hours of admission, a total of 14 were excluded (Figure 1). Overall, 137 patients were enrolled; their baseline characteristics are presented in Table 1. Cause of brain injury was blunt trauma in $70(51 \%)$ patients, vascular in 40 patients $(29 \%)$ and miscellaneous 
242 (mainly post-surgical or endovascular procedure) in 27 (20\%). Mechanical ventilation

243 was initiated for neurological reasons (airway management in comatose patients) in 120

$244(88 \%)$ patients. Other reasons for intubation and mechanical ventilation were acute

245 respiratory failure in 6 patients $(4 \%)$, shock in one patient (1\%), post-operative period in

2466 patients $(4 \%)$, and undetermined in 4 patients $(3 \%)$. The median age was 50 [34 to

24763 ] years, 80 (59\%) patients were male, and the median SAPS II was 46 [36 to 55].

\section{Neurological features of the patients}

249 Main neurological features are presented in Table 2. The median GCS prior to sedation

250

251

252

253

254

255

256

257

258

259

260

261

262

263

264

was 7 [4 to 11]. At the time of inclusion, all patients were deeply sedated (RASS <-3), with $90(66 \%)$ patients exhibiting RASS -5 . Deep sedation was obtained using one $(n=114,83 \%)$, two $(n=21,15 \%)$ or three $(n=2,2 \%)$ hypnotic agents. One hundred twenty-two (89\%) patients received midazolam, $35(26 \%)$ propofol and $5(4 \%)$ sodium thiopental. Sufentanil was administered to 107 (78\%) patients. At inclusion, median FOUR score was 4 [2 to 5]. The most frequently preserved brainstem reflex was the corneal reflex, present in 103 patients (79\%), and grimacing to pain was the most frequently abolished reflex (present in 32 patients, 30\%). The cough reflex was present in 100 patients $(74 \%)$. The proportion of patients with RASS -5 was greater in patients with abolished cough reflex ( $80 \%$ vs. $60 \%, p=0.039)$. Similarly, the cumulative doses administrated at time of clinical exam of midazolam and opioid agents were greater in patients with abolished cough reflex (1.2 vs. $1.9 \mathrm{mg} / \mathrm{kg}, \mathrm{p}=0.005$ and, $5.2 \mathrm{vs.} 8.5 \mu \mathrm{g} / \mathrm{kg}$, $p=0.009$ respectively) (Table 3 ).

Brain imaging was performed for 133 patients (97\%) by a CT scan, of whom 45 (34\%) patients exhibited infra-tentorial lesions including brain stem lesions. 


\section{ICU mortality}

266 Thirty patients (22\%) died in the ICU (Table 1). Causes of death were multi-organ failure

267 in 6 patients (20\%), brain death in 5 patients (17\%) and, withdrawal of life sustaining

268 therapies (WLST) in 16 patients (53\%). Cause of death was not reported for 3 patients

269 (10\%). WLST-related death occurred at day 8 [6-17] (ranging from day 3 to day 48 after

270 admission). SAPSII (OR 1.06 per unit, $p=0.001)$ was significantly greater in non-

271 survivors (Table 4). At admission, GCS were significantly lower (OR 0.80 per unit, $p=$

$2720.004)$ in non-survivors. The proportion of patients with RASS $-5(p=0.32)$ did not

273 statistically differ between the two groups. The corneal (OR 2.69, $p=0.034)$ and cough

274 reflexes (OR 5.12, $p=0.0003$ ) were more frequently abolished in non-survivors. After

275 adjustment to pre-sedation GCS, SAPS-II, and RASS (OR: 5.19, 95\% Cl: [1.92-14.1],

$276 \mathrm{p}=0.001$ ) or midazolam and sufentanyl doses (OR: 8.89, 95\% Cl: [2.64-30.0],

$277 \mathrm{p}=0.0004)$, an abolished cough reflex was associated with ICU mortality.

\section{Other outcomes}

\section{9}

Median duration of sedation was 5 [3 to 10] days while median duration of mechanical ventilation was 13 [8 to 24] days. Median time to awakening was 4 [1 to 12] days following discontinuation of sedation. Delayed awakening was observed in 67 patients (51\%) and delirium in 66 patients (59\%). Eighty-six patients (64\%) developed ventilator associated pneumonia. Among the 103 patients in whom intracranial pressure was monitored, 50 patients (49\%) suffered from at least one episode of elevated intracranial pressure. 
288

289

290

291

292

293

294

295

296

297

298

299

300

301

302

303

304

305

306

307

308

In this prospective, multicenter cohort study we found that, in brain injured patients requiring deep sedation, early abolition of the cough reflex (day 1 ) was associated with ICU mortality after adjustment for severity of illness (i.e. SAPS-II), brain injury (i.e. presedation GCS), depth of sedation (i.e. RASS) and sedative and analgesic doses.

Moreover, abolition of the cough reflex was independent of the type of injury.

These results extend our previous findings obtained in non-brain injured patients(Sharshar et al., 2011a; Rohaut et al., 2017). It supports our hypothesis that mortality could result from dysfunction of the brainstem, which controls vital functions via the autonomic nervous system (Heming et al., 2017). Thus, abolition of the cough reflex could be a clinical marker of dysfunction in the medulla, which integrates cardiovascular and respiratory centers. Interestingly, critical illness is associated with a reduction in heart rate and tidal volume variability, which, as markers of impaired central control, are associated with organ failure, mortality, and weaning failure from MV (Annane et al., 1999; Wysocki et al., 2006) .

The putative mechanisms of brainstem dysfunction can be related to three nonmutually exclusive mechanisms: 1) primary brain injury; 2) neuro-inflammation; 3) oversedation (Benghanem et al., 2020).

(1) Cough reflex abolition may result from a direct brainstem injury related to haemorrhage, axonal lesions, herniation brain swelling etc. Specific assessment of brainstem injury would have required specific brain imaging (e.g. magnetic resonance imaging, diffusion tensor imaging) (Fischer et al., 2016) which was out of the scope of 
309 this observational study. Patient management, including the choice of brain imaging

310 within the first 24 hours, was under the responsibility of ICU-physicians. In this context,

311 CT scan is the most commonly performed exam (Connolly et al., 2012; Geeraerts et al., 312 2018).

313 (2) In addition to the direct injury, systemic inflammation can cause neuro-inflammatory

314 brainstem injuries. These lesions are usually radiologically undetectable. Circulating

315 mediators can directly reach the brainstem through the area postrema. This zone's lack

316 of a blood-brain barrier allows neuro-inflammatory insults and neuronal apoptosis,

317 notably within the medullary autonomic and respiratory centers (Sharshar et al., 2002,

318 2003). As described in septic acute encephalopathy or delirium in ICU, this mechanism

319 could occur as early as 24 hours after brain injury (Mazeraud, Bozza \& Sharshar, 2018;

320 Slooter et al., 2020)

321 (3) Finally, as respiratory centers are sensitive to sedation (Rohaut et al., 2017)

322 especially opioids, cough reflex abolition could be a direct effect of sedation. The dose

323 of sedatives and opioids and the depth of sedation (according to the RASS) were

324 greater in patients with absent cough reflex, which can therefore be considered a

325 marker of oversedation. However, abolition of cough reflex remains associated with

326 mortality after adjustment on sedation levels as well as sedative and analgesic doses,

327 suggesting that its abolition integrates other processes than sedation alone. It would be

328 interesting to test the predictive value of cough reflex abolition against EEG, which may

329 be more accurate to assess depth of sedation.

330 The conclusion of our study is pragmatic; severity and prognostic assessment of brain-

331 injured patients requiring deep sedation should integrate assessment of brainstem 
332 reflexes, especially the cough reflex. This assessment can be performed by using the

333 FOUR score (Wijdicks et al., 2005; Foo, Loan \& Brennan, 2019). It must be noted that

334 information regarding the neurological components of the SAPS-II and SOFA severity

335 scores, as well as of the RASS sedation scale, is limited. Indeed, the SAPS-II and

336 SOFA score include the GCS value before sedation; while the RASS relies solely on the

337 patient's motor reactivity to verbal or non-painful physical stimulation. Brainstem reflex

338 assessment within the first 24 hours of sedation provides clinicians with a

339 comprehensive and temporally integrative neurological evaluation.

340 Limits

341 Our study has several limits. First, the causes of brain injuries are multiple.

342 Nevertheless, except for grimacing to pain and pupillary light reflexes, the neurological

343 patterns were similar among the different subpopulations (Table 2). Our results suggest

344 that the association between cough reflex abolition and ICU mortality is independent

345 from the cause of brain injury. Second, the optimal way to assess the depth of sedation

346 remains a matter of debate. In accordance with our previous findings, we chose to

347 assess the depth of sedation using a specifically designed clinical scale (the RASS;

348 Table 4, model 1). However, since doses of sedation were significantly different within

349 patients with preserved and abolished cough reflex, we also decided to include this

350 parameter in our multivariate analysis (Table 4, model 2). Continuous EEG monitoring

351 and/or determining plasma levels of sedatives could have provided more detail

352 regarding the level of sedation, however these assessments are not routinely

353 undertaken. Based on our results, and without measurement of plasmatic sedation

354 levels, assessing the cause of cough reflex inhibition is not feasible. It would be 
355 interesting to determine the prognostic value of the cough reflex against EEG, and to

356 assess whether its abolition depends on circulating levels of sedatives. Third, as the

357 main cause of death was withdrawal of life-sustaining therapies, our study could have

358 been exposed to the self-fulfilling prophecy bias. However, the proportion of WLST in

359 our study was comparable to other reports (Leblanc et al., 2018). In addition, it is not a

360 common clinical practice to base WLST solely on day 1 neurological examination. In our

361 study, no WLST-related death occurred before day 3. Nevertheless, a neurological

362 examination at day 1,2 , and 3 could have been more valuable than solely at day 1 , and

363 this must be further evaluated. It must also be noted that since the reason for ICU

364 discharge was not prospectively assessed, we cannot rule out that patients have been

365 discharged from ICU for palliation on the ward and have died on the ward. Only ICU

366 mortality at day 28 was addressed. Fourth, our data does not allow any exploration of

367 the causality of brainstem dysfunction. In addition to the proposed mechanisms (i.e

368 primary injury, oversedation or neuroinflammation), the causal link between brainstem

369 failure and multi-organ failure (which was responsible for $20 \%$ of the mortality in our

370 study) has to be explored. Understanding to what extend brainstem dysfunction could

371 be a cause or a consequence of multi-organ failure would need further investigation.

373 Conclusions

374 Taken together, our results suggest that an absence of cough reflex is an independent

375 predictor of ICU-mortality in deeply sedated brain-injured patients. This is an important

376 extension of our previous findings in deeply sedated non-brain-injured ICU patients.

377 Abolition of cough reflex possibly reflects a brainstem dysfunction that could 
378 compromise vital functions. This brainstem dysfunction might result from over- sedation 379 combined with primary and secondary cerebral insults. Assessment of brainstem 380 reflexes may complete SAPS-II and RASS scores for evaluating the severity and depth 381 of sedation, and help predict the prognosis of deeply sedated brain injured patients.

382 Future research could aim at assessing the safety and efficacy of sedation titration 383 aimed at preserving the cough reflex without compromising the control of intracranial 384 pressure in brain-injured patients. 
Details of authors contributions:

386

387

388

389

390

391

392

393

394

395

396

397

398

399

400

401

402

403

404

405

SK, JA, RP, JM, BR and TS contributed to the conception and design of the study. SK, JA, CR, CV, FR, NH, GM, GS, NL and FB performed data acquisition. SK, JA, RP, RB and TS contributed to interpretation and analysis of the data; SK, BR and TS drafted the manuscript; SK, BR, RP, DA, FC, NL, FB and TS critically revised the manuscript; SK, BR and TS gave final approval and agreed to be accountable for all aspects of the work. BR and TS contributed equally to this work.

Acknowledgement: This work is dedicated to the memory of Professor Jean Mantz.

We would like to thank all the members of the "Groupe d'Explorations Neurologiques en Réanimation (GENER)", leaded by Professor SHARSHAR (email: t.sharshar@chsainte-anne.fr), namely: Nicolas ADAM, Jeremy ALLARY, Eric AZABOU, Omar BEN HADJ SALEM, Francis BOLGERT, Antoine BRACONNIER, Alain CARIOU, Patrick CHILLET, Fabrice CHRETIEN, Vincent DEGOS, Sophie DEMERET, Raphael GAILLARD, Stephane GAUDRY, Nicholas HEMING, Tarik HISSEM, Stanislas KANDELMAN, Jonathan LEVY, Yann L'HERMITTE, Eric MAGALHAES, Jean MANTZ, Aurélien MAZERAUD, Régine MORIZOT-KOUTLIDIS, Lionel NACCACHE, Vincent NAVARRO, Hervé OUTIN, Andrea POLITO, Benjamin ROHAUT, Tarek SHARSHAR, Shidasp SIAMI, Romain SONNEVILLE, Pierre ROCHETEAU, Franck VERDONK, Chuyen VU DINH and Nicolas WEISS. 
406

407

408

409

410

411

412

413

414

415

416

417

418

419

420

421

422

423

424

425

426

427

428

429

430

431

432

433

434

435

436

437

438

439

440

441

442

443

\section{References}

Annane D, Trabold F, Sharshar T, Jarrin I, Blanc AS, Raphael JC, Gajdos P. 1999. Inappropriate sympathetic activation at onset of septic shock: a spectral analysis approach. American Journal of Respiratory and Critical Care Medicine 160:458-465. DOI: 10.1164/ajrccm.160.2.9810073.

Azabou E, Rohaut B, Heming N, Magalhaes E, Morizot-Koutlidis R, Kandelman S, Allary J, Moneger G, Polito A, Maxime V, Annane D, Lofaso F, Chrétien F, Mantz J, Porcher R, Sharshar T. 2017. Early impairment of intracranial conduction time predicts mortality in deeply sedated critically ill patients: a prospective observational pilot study. Annals of Intensive Care 7:63. DOI: 10.1186/s13613-017-0290-5.

Azabou E, Rohaut B, Porcher R, Heming N, Kandelman S, Allary J, Moneger G, Faugeras F, Sitt JD, Annane D, Lofaso F, Chrétien F, Mantz J, Naccache L, Sharshar T. 2018. Mismatch negativity to predict subsequent awakening in deeply sedated critically ill patients. British Journal of Anaesthesia 0. DOI: 10.1016/j.bja.2018.06.029.

Benghanem S, Mazeraud A, Azabou E, Chhor V, Shinotsuka CR, Claassen J, Rohaut B, Sharshar T. 2020. Brainstem dysfunction in critically ill patients. Critical Care 24:5. DOI: 10.1186/s13054-019-2718-9.

Connolly ES, Rabinstein AA, Carhuapoma JR, Derdeyn CP, Dion J, Higashida RT, Hoh BL, Kirkness CJ, Naidech AM, Ogilvy CS, Patel AB, Thompson BG, Vespa P, American Heart Association Stroke Council, Council on Cardiovascular Radiology and Intervention, Council on Cardiovascular Nursing, Council on Cardiovascular Surgery and Anesthesia, Council on Clinical Cardiology. 2012. Guidelines for the management of aneurysmal subarachnoid hemorrhage: a guideline for healthcare professionals from the American Heart Association/american Stroke Association. Stroke 43:17111737. DOI: 10.1161/STR.0b013e3182587839.

von Elm E, Altman DG, Egger M, Pocock SJ, Gøtzsche PC, Vandenbroucke JP, STROBE Initiative. 2007. The Strengthening the Reporting of Observational Studies in Epidemiology (STROBE) statement: guidelines for reporting observational studies. Lancet (London, England) 370:1453-1457. DOI: 10.1016/S0140-6736(07)61602-X.

Ely EW, Inouye SK, Bernard GR, Gordon S, Francis J, May L, Truman B, Speroff T, Gautam S, Margolin R, Hart RP, Dittus R. 2001. Delirium in mechanically ventilated patients: validity and reliability of the confusion assessment method for the intensive care unit (CAM-ICU). JAMA 286:2703-2710.

Ely EW, Truman B, Shintani A, Thomason JWW, Wheeler AP, Gordon S, Francis J, Speroff T, Gautam S, Margolin R, Sessler CN, Dittus RS, Bernard GR. 2003. Monitoring sedation status over time in ICU patients: reliability and validity of the Richmond Agitation-Sedation Scale (RASS). JAMA 289:29832991. DOI: 10.1001/jama.289.22.2983.

Fischer DB, Boes AD, Demertzi A, Evrard HC, Laureys S, Edlow BL, Liu H, Saper CB, Pascual-Leone A, Fox MD, Geerling JC. 2016. A human brain network derived from coma-causing brainstem lesions. Neurology 87:2427-2434. DOI: 10.1212/WNL.0000000000003404.

Foo CC, Loan J, Brennan PM. 2019. The relationship of the FOUR score to patient outcome: a systematic review. Journal of Neurotrauma. DOI: 10.1089/neu.2018.6243. 
444

445

446

447

448

449

450

451

452

453

454

455

456

457

458

459

460

461

462

463

464

465

466

467

468

469

470

471

472

473

474

475

476

477

478

479

480

481

482

Geeraerts T, Velly L, Abdennour L, Asehnoune K, Audibert G, Bouzat P, Bruder N, Carrillon R, Cottenceau V, Cotton F, Courtil-Teyssedre S, Dahyot-Fizelier C, Dailler F, David J-S, Engrand N, Fletcher D, Francony G, Gergelé L, Ichai C, Javouhey É, Leblanc P-E, Lieutaud T, Meyer P, Mirek S, Orliaguet G, Proust F, Quintard H, Ract C, Srairi M, Tazarourte K, Vigué B, Payen J-F, French Society of Anaesthesia, Intensive Care Medicine, in partnership with Association de neuro-anesthésieréanimation de langue française (Anarlf), French Society of Emergency Medicine (Société Française de Médecine d'urgence (SFMU), Société française de neurochirurgie (SFN), Groupe francophone de réanimation et d'urgences pédiatriques (GFRUP), Association des anesthésistes-réanimateurs pédiatriques d'expression française (Adarpef). 2018. Management of severe traumatic brain injury (first 24hours). Anaesthesia, Critical Care \& Pain Medicine 37:171-186. DOI: 10.1016/j.accpm.2017.12.001.

Heming N, Mazeraud A, Verdonk F, Bozza FA, Chrétien F, Sharshar T. 2017. Neuroanatomy of sepsisassociated encephalopathy. Critical Care (London, England) 21:65. DOI: 10.1186/s13054-017-1643$\mathrm{z}$.

Le Gall JR, Neumann A, Hemery F, Bleriot JP, Fulgencio JP, Garrigues B, Gouzes C, Lepage E, Moine P, Villers D. 2005. Mortality prediction using SAPS II: an update for French intensive care units. Critical Care (London, England) 9:R645-652. DOI: 10.1186/cc3821.

Leblanc G, Boutin A, Shemilt M, Lauzier F, Moore L, Potvin V, Zarychanski R, Archambault P, Lamontagne F, Léger C, Turgeon AF. 2018. Incidence and impact of withdrawal of life-sustaining therapies in clinical trials of severe traumatic brain injury: A systematic review. Clinical Trials (London, England) 15:398-412. DOI: 10.1177/1740774518771233.

Marshall A, Altman DG, Holder RL, Royston P. 2009. Combining estimates of interest in prognostic modelling studies after multiple imputation: current practice and guidelines. $B M C$ medical research methodology 9:57. DOI: 10.1186/1471-2288-9-57.

Mazeraud A, Bozza FA, Sharshar T. 2018. Sepsis-associated Encephalopathy Is Septic. American Journal of Respiratory and Critical Care Medicine 197:698-699. DOI: 10.1164/rccm.201712-2593ED.

McCabe W, Jackson G. 1962. Gram-negative bacteremia. I. Etiology and ecology. Archives of Internal Medicine:847-853.

Oddo M, Crippa IA, Mehta S, Menon D, Payen J-F, Taccone FS, Citerio G. 2016. Optimizing sedation in patients with acute brain injury. Critical Care (London, England) 20:128. DOI: 10.1186/s13054-0161294-5.

Rohaut B, Porcher R, Hissem T, Heming N, Chillet P, Djedaini K, Moneger G, Kandelman S, Allary J, Cariou A, Sonneville R, Polito A, Antona M, Azabou E, Annane D, Siami S, Chrétien F, Mantz J, Sharshar T, Groupe d'Exploration Neurologique en Réanimation (GENER). 2017. Brainstem response patterns in deeply-sedated critically-ill patients predict 28-day mortality. PloS One 12:e0176012. DOI: 10.1371/journal.pone.0176012.

Sharshar T, Gray F, Lorin de la Grandmaison G, Hopkinson NS, Ross E, Dorandeu A, Orlikowski D, Raphael J-C, Gajdos P, Annane D. 2003. Apoptosis of neurons in cardiovascular autonomic centres triggered by inducible nitric oxide synthase after death from septic shock. Lancet 362:1799-1805. 
483

484

485

486

487

488

489

490

491

492

493

494

495

496

497

498

499

500

501

502

503

504

505

506

507

508

509

510

511

512

513

514

515

516
Sharshar T, Gray F, Poron F, Raphael JC, Gajdos P. 2002. Multifocal necrotizing leukoencephalopathy in septic shock. Crit Care Med 30. DOI: 10.1097/00003246-200210000-00031.

Sharshar T, Porcher R, Siami S, Rohaut B, Bailly-salin J, Hopkinson NS, Clair B, Guidoux C, lacobone E, Sonneville R, Polito A, Aboab J, Gaudry S, Morla O, Amouyal G, Azuar J, Allary J, Vieillard-baron A, Wolff M, Cariou A, Annane D. 2011a. Brainstem responses can predict death and delirium in sedated patients in intensive care unit*. Critical Care Medicine 39:1960-1967. DOI: 10.1097/CCM.0b013e31821b843b.

Sharshar T, Porcher R, Siami S, Rohaut B, Bailly-Salin J, Hopkinson NS, Clair B, Guidoux C, lacobone E, Sonneville R, Polito A, Aboab J, Gaudry S, Morla O, Amouyal G, Azuar J, Allary J, Vieillard-Baron A, Wolff M, Cariou A, Annane D, Paris-Ouest Study Group on Neurological Effect of Sedation (POSGNES). 2011b. Brainstem responses can predict death and delirium in sedated patients in intensive care unit. Critical Care Medicine 39:1960-1967. DOI: 10.1097/CCM.0b013e31821b843b.

Shehabi Y, Bellomo R, Kadiman S, Ti LK, Howe B, Reade MC, Khoo TM, Alias A, Wong Y-L, Mukhopadhyay A, McArthur C, Seppelt I, Webb SA, Green M, Bailey MJ, Sedation Practice in Intensive Care Evaluation (SPICE) Study Investigators and the Australian and New Zealand Intensive Care Society Clinical Trials Group. 2018. Sedation Intensity in the First 48 Hours of Mechanical Ventilation and 180-Day Mortality: A Multinational Prospective Longitudinal Cohort Study. Critical Care Medicine 46:850-859. DOI: 10.1097/CCM.0000000000003071.

Slooter AJC, Otte WM, Devlin JW, Arora RC, Bleck TP, Claassen J, Duprey MS, Ely EW, Kaplan PW, Latronico N, Morandi A, Neufeld KJ, Sharshar T, MacLullich AMJ, Stevens RD. 2020. Updated nomenclature of delirium and acute encephalopathy: statement of ten Societies. Intensive Care Medicine 46:1020-1022. DOI: 10.1007/s00134-019-05907-4.

Vincent JL, Moreno R, Takala J, Willatts S, De Mendonça A, Bruining H, Reinhart CK, Suter PM, Thijs LG. 1996. The SOFA (Sepsis-related Organ Failure Assessment) score to describe organ dysfunction/failure. On behalf of the Working Group on Sepsis-Related Problems of the European Society of Intensive Care Medicine. Intensive Care Medicine 22:707-710.

White IR, Royston P, Wood AM. 2011. Multiple imputation using chained equations: Issues and guidance for practice. Statistics in Medicine 30:377-399. DOI: 10.1002/sim.4067.

Wijdicks EFM, Bamlet WR, Maramattom BV, Manno EM, McClelland RL. 2005. Validation of a new coma scale: The FOUR score. Annals of Neurology 58:585-593. DOI: 10.1002/ana.20611.

Wysocki M, Cracco C, Teixeira A, Mercat A, Diehl J-L, Lefort Y, Derenne J-P, Similowski T. 2006. Reduced breathing variability as a predictor of unsuccessful patient separation from mechanical ventilation. Critical Care Medicine 34:2076-2083. DOI: 10.1097/01.CCM.0000227175.83575.E9. 
Figure 1

Flow chart 


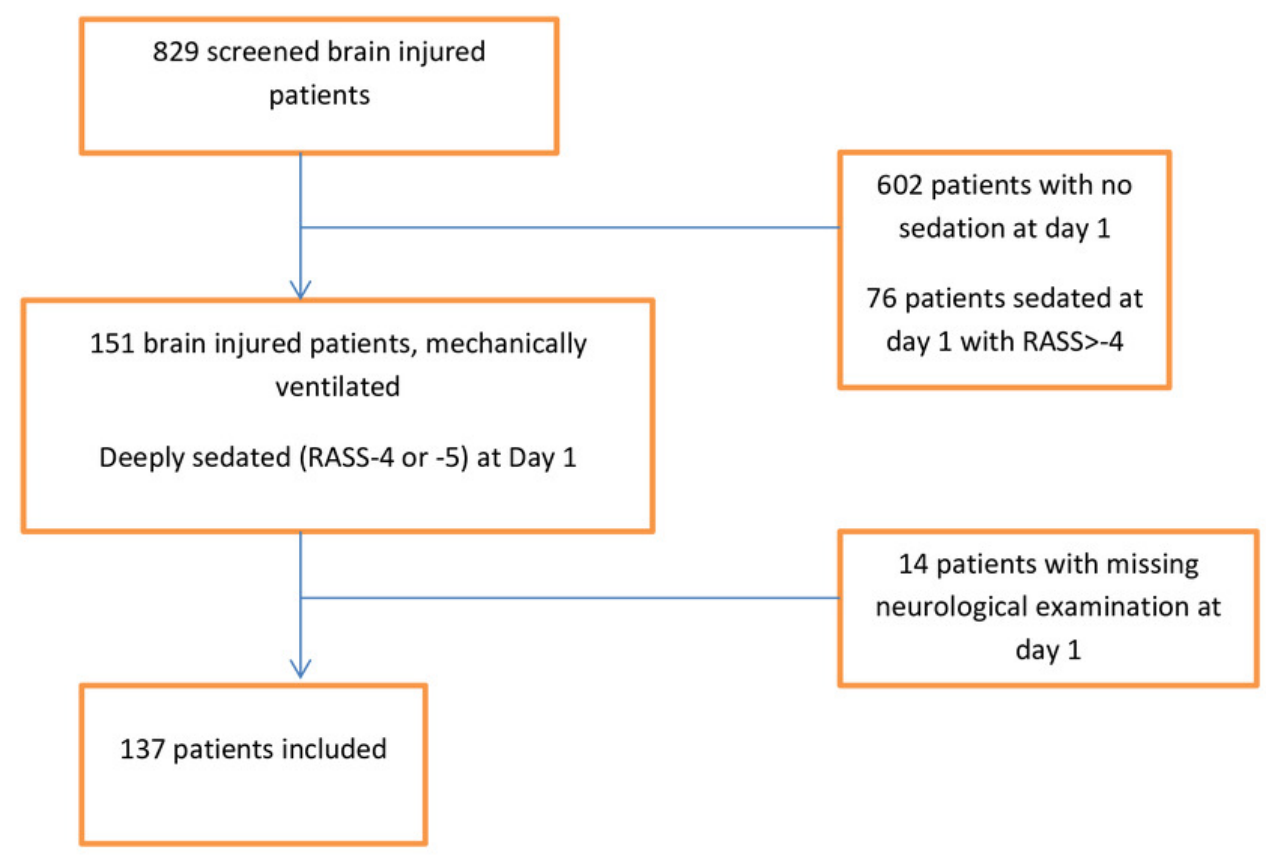




\section{Table $\mathbf{1}$ (on next page)}

Characteristics of patients and ICU outcome

N: number of evaluated patients; SAPS II: Simplified Acute Physiology Score; GCS: Glasgow Coma Scale; SOFA: sepsis related organ failure assessment; ICU: Intensive Care Unit; TBI: Traumatic brain injury. IQR: Interquartile range (Q1 to Q3). * Patients who died while sedated could not be evaluated; † Patients who died while sedation or before awakening could not be evaluated. 
1 Table 1. Characteristics of patients and ICU outcome.

\begin{tabular}{|c|c|c|c|c|c|}
\hline Variable & $\mathbf{N}$ & All patients & TBI & Vascular & Other \\
\hline No. patients (\% of total) & & 137 & $70(51)$ & 40 (29) & $27(20)$ \\
\hline Age (years) - median (IQR) & 137 & 50 (34 to 63$)$ & 39 (25 to 53$)$ & 60 (52 to 66$)$ & 53 (40 to 77 ) \\
\hline Female - no. (\%) & 137 & $56(41)$ & $16(23)$ & $27(68)$ & $13(50)$ \\
\hline SAPS-II - median (IQR) & 129 & 46 (36 to 55$)$ & 41 (33 to 53 ) & 48 (38 to 52$)$ & 51 (44 to 60$)$ \\
\hline Initiation of mechanical ventilation - no. (\%) & 137 & & & & \\
\hline Coma & & $120(88)$ & $68(97)$ & $34(85)$ & $18(67)$ \\
\hline Acute respiratory failure & & $6(4)$ & $0(0)$ & $2(5)$ & $4(15)$ \\
\hline Shock & & $1(1)$ & $0(0)$ & $0(0)$ & $1(4)$ \\
\hline Surgery/procedure & & $6(4)$ & $0(0)$ & $4(10)$ & $2(7)$ \\
\hline Other & & $4(3)$ & $2(3)$ & $0(0)$ & $2(7)$ \\
\hline McCabe score 1 - no. (\%) & 135 & $106(79)$ & $64(93)$ & $22(55)$ & $20(77)$ \\
\hline GCS at admission - median (IQR) & 132 & 7 (4 to 10$)$ & 7 (5 to 10$)$ & 7 (4 to 10$)$ & $6(3$ to 11$)$ \\
\hline SOFA at admission - median (IQR) & 132 & $6(4$ to 8$)$ & 5 (4 to 8$)$ & 5 (4 to 7$)$ & 7 (4 to 9$)$ \\
\hline \multicolumn{6}{|l|}{ Outcome } \\
\hline Duration of mechanical Ventilation (days) - median (IQR) & 131 & 13 (8 to 24$)$ & $14(10$ to 23$)$ & 13 (8 to 20$)$ & $9(5$ to 23$)$ \\
\hline Duration of sedative infusion (days) - median (IQR) & 133 & 5 (3 to 10$)$ & 5 (3 to 12$)$ & $4(3$ to 11$)$ & 4 (3 to 7$)$ \\
\hline Occurrence of elevated intracranial pressure - no. (\%) & 103 & 50 (49) & $31(48)$ & $16(50)$ & $3(43)$ \\
\hline Occurrence of ventilator acquired pneumonia - no. (\%) & 135 & $86(64)$ & $50(72)$ & $25(62)$ & $11(42)$ \\
\hline Time to awakening (days) - median (IQR) & $131^{*}$ & $4(1$ to 12$)$ & $4(1$ to 12$)$ & $6(2$ to 17$)$ & $1(0$ to 5$)$ \\
\hline Occurrence of delayed awakening - no. (\%) & $131^{*}$ & $67(51)$ & $36(51)$ & $23(64)$ & $8(32)$ \\
\hline Occurrence of delirium - no. (\%) & $112^{\dagger}$ & $66(59)$ & $46(75)$ & $12(40)$ & $8(38)$ \\
\hline Duration of ICU stay (days) - median (IQR) & 136 & 19 (11 to 32$)$ & 19 (11 to 32$)$ & $20(12$ to 36$)$ & 15 (8 to 24$)$ \\
\hline Death in ICU - no. (\%) & 137 & $30(22)$ & $12(17)$ & $11(28)$ & $7(26)$ \\
\hline
\end{tabular}

2

3 N: number of evaluated patients; SAPS II: Simplified Acute Physiology Score; GCS:

4 Glasgow Coma Scale; SOFA: sepsis related organ failure assessment; ICU: Intensive

5 Care Unit; TBI: Traumatic brain injury. IQR: Interquartile range (Q1 to Q3).

6 * Patients who died while sedated could not be evaluated;

7 † Patients who died while sedation or before awakening could not be evaluated. 


\section{Table 2 (on next page)}

Neurological assessment at inclusion

$\mathrm{N}$ : number of evaluated patients; IQR: Interquartile range (Q1 to Q3); RASS Richmond Assessment Sedation Scale; GCS Glasgow Coma Scale; FOUR score Full outline of Unresponsiveness; TBI: Traumatic brain injury. 
1 Table 2. Neurological assessment at inclusion.

\begin{tabular}{|c|c|c|c|c|c|}
\hline Variable & $\mathbf{N}$ & All patients & TBI & Vascular & Other \\
\hline No. patients (\% of total) & & 137 & $70(51)$ & $40(29)$ & $27(20)$ \\
\hline RASS $-5-$ no. (\%) & 137 & $90(66)$ & $54(77)$ & $21(52)$ & $15(56)$ \\
\hline \multicolumn{6}{|l|}{ Neurologic response } \\
\hline GCS motor - median (IQR) & 124 & 1 (1 to 1$)$ & 1 (1 to 1$)$ & 1 (1 to 2$)$ & 1 (1 to 3 ) \\
\hline GCS ocular - median (IQR) & 124 & 1 (1 to 1$)$ & 1 (1 to 1$)$ & 1 (1 to 1$)$ & 1 (1 to 1$)$ \\
\hline FOUR Score- median (IQR) & 111 & $4(2$ to 5$)$ & 4 ( 2 to 5$)$ & $4(2$ to 5$)$ & $4(2$ to 7$)$ \\
\hline Eye response - median (IQR) & 113 & 0 (0 to 0$)$ & 0 (0 to 0$)$ & 0 (0 to 0$)$ & 0 (0 to 0$)$ \\
\hline Motor response - median (IQR) & 113 & $0(0$ to 0$)$ & 0 (0 to 0$)$ & $0(0$ to 0$)$ & 0 (0 to 2$)$ \\
\hline Brainstem reflexes - median (IQR) & 111 & 4 (2 to 4$)$ & 4 ( 2 to 4$)$ & $4(2$ to 4$)$ & 3 (2 to 4$)$ \\
\hline Respiration - median (IQR) & 113 & $0(0$ to 1$)$ & 0 (0 to 1$)$ & $0(0$ to 1$)$ & 1 (0 to 1$)$ \\
\hline \multicolumn{6}{|l|}{ Brainstem reflexes impairment } \\
\hline Pupillary light reflex - no. (\%) & 134 & $55(41)$ & $29(42)$ & $19(49)$ & $7(27)$ \\
\hline Corneal reflex - no. (\%) & 131 & $28(21)$ & $15(23)$ & $7(18)$ & $6(23)$ \\
\hline Grimacing to pain - no. (\%) & 108 & $76(70)$ & $51(86)$ & $14(48)$ & $11(55)$ \\
\hline Cough reflex - no. (\%) & 135 & $35(16)$ & $19(28)$ & $9(22)$ & $7(27)$ \\
\hline Myosis - no. (\%) & 136 & $69(51)$ & $37(54)$ & $19(48)$ & $13(48)$ \\
\hline
\end{tabular}

2

$3 \mathrm{~N}$ : number of evaluated patients; IQR: Interquartile range (Q1 to Q3); RASS Richmond

4 Assessment Sedation Scale; GCS Glasgow Coma Scale; FOUR score Full outline of

5 Unresponsiveness; TBI: Traumatic brain injury. 


\section{Table 3 (on next page)}

Comparison of sedation according to the presence/absence of cough reflex

IQR: Interquartile range (Q1 to Q3); Sedation and analgesics doses are cumulative doses from introduction to neurological assessment (12 to 24 hours); 2 patients were excluded from this analysis, for missing sedation data. * Sufentanyl-equivalent dose (for the $18 \%$ of patients which received fentanyl, doses where divided by 10$)$. 
1 Table 3. Comparison of sedation according to the presence/absence of cough

2 reflex.

\begin{tabular}{|c|c|c|c|}
\hline & \multicolumn{2}{|c|}{ Cough reflex } & \multirow[b]{2}{*}{$\mathbf{P}$} \\
\hline & Present & Absent & \\
\hline No. patients & 100 & 35 & \\
\hline \multicolumn{4}{|l|}{ Hypnotic agent (several possible) } \\
\hline Midazolam - no. (\%) & $86(86)$ & $34(97)$ & 0.11 \\
\hline Propofol - no. (\%) & $25(25)$ & $10(29)$ & 0.66 \\
\hline Thiopental — no. (\%) & $1(1)$ & $4(11)$ & 0.016 \\
\hline Midazolam dose (mg/kg) — median (IQR) & $1.2(0.7$ to 2.1$)$ & $1.9(1.2$ to 2.3$)$ & 0.005 \\
\hline Propofol dose $(\mathrm{mg} / \mathrm{kg})-$ median (IQR) & 17.7 (10.2 to 22.6$)$ & 37.1 (18.4 to 44.4$)$ & 0.12 \\
\hline Morphinic agent — no. (\%) & & & 0.60 \\
\hline No & $4(4)$ & $0(0)$ & \\
\hline Sufentanyl & $78(78)$ & $27(77)$ & \\
\hline Fentanyl & $18(18)$ & $8(23)$ & \\
\hline Morphinic dose $(\mu \mathrm{g} / \mathrm{kg}) *-$ median (IQR) & $3.9(2.2$ to 7.4$)$ & 6.7 (3.8 to 10.3 ) & 0.006 \\
\hline SAPS-II — median (IQR) & 46 (36 to 55 ) & 46 (34 to 55 ) & 0.76 \\
\hline SOFA at admission - median (IQR) & 5 (4 to 8$)$ & 6 (5 to 8$)$ & 0.27 \\
\hline RASS -5 - no. (\%) & $60(60)$ & $28(80)$ & 0.039 \\
\hline
\end{tabular}

3

4 IQR: Interquartile range (Q1 to Q3); Sedation and analgesics doses are cumulative

5 doses from introduction to neurological assessment (12 to 24 hours); 2 patients were

6 excluded from this analysis, for missing sedation data.

$7 \quad{ }^{*}$ Sufentanyl-equivalent dose (for the $18 \%$ of patients which received fentanyl, doses

8 where divided by 10). 


\section{Table 4 (on next page)}

Association of neurological response with ICU death

* Sufentanyl-equivalent dose; OR: odds ratio; aOR: adjusted odds ratio; SAPS II Simplified Acute Physiology Score; RASS: Richmond Assessment Sedation Scale. 
1 Table 4. Association of neurological response with ICU death.

\begin{tabular}{|c|c|c|c|c|c|c|}
\hline & \multicolumn{2}{|l|}{ Unadjusted } & \multicolumn{2}{|l|}{ Multiple model 1} & \multicolumn{2}{|l|}{ Multiple model 2} \\
\hline & OR $(95 \% \mathrm{Cl})$ & $\mathbf{P}$ & aOR (95\% CI) & $\mathbf{P}$ & aOR (95\% CI) & $\mathbf{P}$ \\
\hline SAPS-II (per unit) & $1.06(1.02-1.09)$ & 0.002 & $1.04(1.00-1.08)$ & 0.086 & $1.04(0.99-1.08)$ & 0.092 \\
\hline GCS at admission (per unit) & $0.80(0.69-0.93)$ & 0.004 & $0.88(0.74-1.04)$ & 0.13 & $0.87(0.72-1.04)$ & 0.12 \\
\hline RASS -5 & $1.58(0.64-3.91)$ & 0.32 & $0.74(0.26-2.17)$ & 0.59 & - & - \\
\hline Midazolam dose $(\mathrm{mg} / \mathrm{kg})$ & $0.69(0.44-1.11)$ & 0.12 & - & - & $0.42(0.14-1.25)$ & 0.12 \\
\hline Morphinic dose $(\mu \mathrm{g} / \mathrm{kg})^{*}$ & $0.97(0.88-1.08)$ & 0.59 & - & - & $1.01(0.82-1.25)$ & 0.91 \\
\hline Absent cough reflex & $5.12(2.13-12.4)$ & 0.0003 & $5.19(1.92-14.1)$ & 0.001 & $8.89(2.64-30.0)$ & 0.0004 \\
\hline Absent corneal reflex & $2.69(1.08-6.68)$ & 0.034 & $1.71(0.57-5.10)$ & 0.34 & $1.66(0.54-5.08)$ & 0.38 \\
\hline$c$ index $(95 \% \mathrm{Cl})$ & & & $0.810(0.726-0.893)$ & & $0.852(0.773-0.931)$ & \\
\hline
\end{tabular}

* Sufentanyl-equivalent dose; OR: odds ratio; aOR: adjusted odds ratio; SAPS II

5 Simplified Acute Physiology Score; RASS: Richmond Assessment Sedation Scale. 